\title{
Design and Implementation of Sports Information System Based on new media context
}

\author{
Qingqing Wang \\ Zhengzhou Institute of Technology, Zhengzhou 450044, China \\ wagnqq@163.com
}

Key words: New Media, Sports Media and Strategy.

\begin{abstract}
Under the new media environment presents new information and communication features, the audience demand for new changes. Thus, the spread of sports culture must adapt to this new communication environment, and actively adjust communication strategies to enhance the impact of the spread of sports culture and competitiveness.
\end{abstract}

\section{Introduction}

New media is not only to provide people with information, provide entertainment, but also on people's thinking, ways of thinking, cultural ideas, behavior and so had a significant impact [1].

The rise of new media for the attention of sports, the pursuit of sports and cultural facilities provided. In the sports culture spread and development of modern media also played a major role to play therein [1]. To further spread of sports culture, heritage and the development of sports culture, we must do the role of new media in depth analysis and discussion, on this basis, the scientific use of the media, sports and actively choose to implement the new media environment.

\section{Propagation characteristics ofthe new mediaenvironment}

Interactive participatory. The basic mode of transmission of traditional media is one-way communication and linear transmission. This mode of transmission has led to the spread of the exchange between the subject and the audience is blocked, and the dissemination of information and feedback lag and latency [2]. Network, microblogging, mobile phone text messages and other new media appears to overcome these shortcomings of traditional media has changed the audience in information dissemination activities in the passive situation, promoting the spread of the body interaction, between the media and the audience. In the new media environment, everyone can participate in information dissemination activities, the freedom to publish, transmit or comment on the information. According to statistics, China Internet Network Information Center reported the latest release, as of the end of December 2012, the number of Internet users in China reached 564 million, the number of 420 million mobile phone users, 309 million microblogging users. The rapid growth of these new media users have greatly changed the original propagation environment, and promote the dissemination of information in the audience at the primary and enthusiasm to achieve the dissemination of personal information and personalized.

Quick timeliness.The rapid development of new media technology breaks through the limitations of traditional media, the dissemination of information on the time and space to achieve a full-time information, at full speed, spread the whole field. Information on the production of new media is simple, no special complex and cumbersome editing, production and publishing, therefore, the information was produced simultaneously and spread out in the incident. In addition, with the development of fiber-optic communication systems, network communication speed increased from tens of thousands of bytes per second to billions of bytes per second, the new media users can at any time and place to disseminate information and receive instant messages. Therefore, the propagation speed of the new media faster than traditional media, communication activities can be carried out at the same time the event occurred, geographical and fewer space constraints, only the device and transmit signals, you can publish information [3]. 
Facilitate diversity.Compared with the traditional media, new media content or both in the form of easy to have diverse characteristics. New media to support new technologies as a means to provide information on the content of the mass of living and learning needs of the audience, entertainment and other aspects of interaction. In addition, new media and more for the audience to provide free information and therefore more popular [3]. Meanwhile, new ways and means of dissemination of information but also a wide variety of media, the audience can receive information through the network, smart phones, mobile TV and other media. But also a variety of forms of information, text, pictures and videos, the audience can either read the information can also listen to the information and to see the information. In short, in the context of new media, multimedia integration has become a trend among traditional media boundaries between traditional media and new media continue to be digested, while the boundaries of time and space limits the dissemination of information, as well as information disseminators and recipients boundaries between are also constantly being digested.

\section{Development status of Chinese Sports Culture Communication}

Sports Culture is the sum of the material system of human sports, and spiritual culture. Sports culture is reflected and concentrated expression of the human aesthetic sense of human social life sports. Sports Culture Communication refers to the sport as the object passes through certain media process. Sports Media experienced by the traditional means of communication to modern means of communication change, the promoter is to develop media communication technologies. Among them, TV, newspapers, websites of traditional media, sports and cultural dissemination [2].

TV.TV as a traditional mass media, has been the main way that the audience accepts and channels of sports information. It can be said, people's perception of sports, for understanding the spirit of sport and culture mainly through television. TV instrumental in promoting the fitness aspect.

Public Newspapers.Here mainly refers to sports newspapers. At present, China's sports special feature about 50 species, in addition, many integrated class also has some sports newspaper columns, and information dissemination some dynamic aspects of the sport. With the new media, driven by some of the network emerged newspapers played a role should not be overlooked in the sports culture of information dissemination.

Professional Website. From the perspective of sports information dissemination functions, comprehensive website bear a larger proportion of the workload. Small part of the sport of professional website will regularly publish some of the sports information, however, is not the amount of information, the audience is not much, the speed is not too fast. From the point of view of the spread of content, whether it is a comprehensive website, or professional Takaoka Station, is to spread the sports news mainly to introduce sports organizations, sports, science knowledge, information and other sporting goods, supplemented.

\section{The new sports and cultural changes in the spread of the new media environment}

Under the new media environment, information dissemination and acceptance of methods have undergone tremendous changes. This change propagation environment also spread sports culture had a great influence. Sports and cultural modes of transmission also will be changed.

One-way communication to two-way propagation [1]. Internet technology development, and for the majority of the audience raised a public interactive information platform. Microblogging, SMS, micro-letters and other emerging new media, not only changed the sports culture propagation environment, but also led to changes in the way of sports and cultural dissemination. Many professional media organizations have opened up new channels of communication media, to expand its influence spread.

Obvious trend of media convergence.Under the new media environment, the way the audience receives information showing a diverse, personalized features. Sports Culture Communication to adapt to this new change, from the content, form and other aspects of the reform, the use of interactive multimedia collaborative approach to enhance the influence of sports and cultural 
dissemination. First of content, many media outlets have begun to set up the audience to participate in the plate, and reproduced using the micro-blog, posts and micro-channel and network, or the column in reference to Internet users point of view. Secondly formally, sports and cultural dissemination of information both plane static text and pictures, there are also three-dimensional moving images with audio and video.

Dissemination activities are more user-centered.Traditional media are often based on the spread of the main center, which according to its own characteristics and the way information is organized and publishing. The new media is "Social, Location, Mobile", it is socialized, user-centric and mobile technology transfer. Under the new media environment, where the audience, the media, and information on where. Under the new media environment, information dissemination can be defined as information services, which is close to the audience and intimate information services. The audience cannot be bound by time and place, the freedom to accept the initiative, dissemination and review a variety of sporting and cultural information.

\section{Sports Culture Communication strategies in the new media environment}

Sports culture as an important part of the social and cultural impact on human extensive and far-reaching. In the context of new media, sports and cultural dissemination should actively explore new paths, find new strategies to deal with the media.

Depend on the role of new media in order to enhance the integration of open horizons of Sports Culture and Communication [4]. Although sport originated in ancient times of human civilization, but due to inconvenient transportation, communication among the few regions, which makes the exchange of sports, heritage is limited to be within a small range. Meanwhile, the long feudal shackles, sports skills, miscellaneous sports, sports ideology, also limited to mentoring, passing between father and son, and the boundaries between sports guarded the door first, different sports genre, category, area sports exchanges very restrictive, less sports and cultural exchanges. Even in modern times, this idea still exists in the national sports great brand, as is the national sport of the rich features, people will their technical skills as a private thing to be protected. To the contemporary period in the development of market economy, sports highlights due to its market value, making communication between sport martial detentions is covered with a coat of business. From sports and cultural development, these ideas are not conducive to narrow sports culture from each other, the integration of development.

Shaping Sports Media Brand.Under the new media context, Sports Media must spread from reality, personality style characteristics, and build audiences spread brand recognition, can you stand firm in the fierce competition [5]. Sports culture spread a brand, is based on the spread of body positioning spread, spread through the analysis and dissemination of the body to explore the unique advantages of resources, to develop a strategy for long-term sustainable development of sports culture propagation, and in order to establish an attractive and Sports and cultural concern about the spread of products. For example, CCTV5 status by virtue of national television, with financial, material and manpower advantages on. CCTV5 and CCTV network, China Network Television's sports channel has almost become a major domestic and international sporting events dedicated channel, the AFC Champions League, World Cup, Olympic Games and other major sporting events become fixed spread of CCTV sports channel brand. CCTV broadcast in major sports events and has a powerful advantage cannot match. But this does not affect other media in the dissemination of sports events and sports culture development. Some local television stations from their own reality, to explore a number of effective development path. Such as Henan TV's "martial arts style" section is a good exploration and attempt to create a national television broadcast to the provincial martial arts for the content of the longest, highest ratings record.

Using network media communication advantages to create online media advantage in the spread of sports culture. In all the new media, the online media has some other media information integration capabilities, and therefore is an integrated media network media. It can be a collection of all of its media information through links, shared means of sharing resources with other media. Therefore, attention to the construction of sports sites, take advantage of online media dissemination, 
professional sports media an important part of the construction. Currently, from sports to improve the site's characteristics, personality and work hard to create their own unique qualities sports sites, giving audiences a unique sport sports and cultural information services. Professional sports website in commercial operation, according to the market demand, a modest package, to carry out an appropriate marketing strategies to increase referrals propaganda network to expand the site in the sports audience influence.

Expand the role of visual media in the spread of sports culture [5]. Looking back on the domestic sports television dramas, it spread of sports culture has played an indelible contribution to the 1957 advent of the "Women's Basketball No. 5" to the 1981 launch of the "gull", and even the 2000, 2001 have been broadcast of "female Huainan soldiers", "defensive back", "Shaolin Soccer" and so on. All they gave people a strong visual impact and aesthetic sense, these people into film and television works with a different, little-known sports scenes of life, enhance people's understanding of the sport, the athletes struggle deepened perception. With the broadcast of these television dramas, once appeared in the national sports craze, sports culture had a tremendous impact on public life. In recent years, with the expansion of China's film and television dramas impact on the international film, television dramas sports people of the world have had a significant impact, which is China's sports culture dissemination and exchange in the world, also played an important impact. After the mid-seventies, film and television industry in our country a "martial arts film" hot, "Shaolin Temple", "Fearless", "Chen Zhen" and "The Legend of Bruce Lee" and a number of film and television dramas have also praised people. We can say that this particular sport martial arts form, in the role of film and television dramas, and for the people has also had a significant impact, which is also to the people, to showcase the unique charm of the world of sports.

\section{Summary}

Under the new media environment, the needs of the audience showing a variety of information, freedom and personalized features. Sports Culture Communication must also adapt to this new trend, the rapid dissemination of timely adjustment mode, take a multimedia interactive collaboration, more active coordination and communication with the audience, mobilize interest to different audiences, and increase the influence of sports and cultural dissemination.

\section{References}

[1] L. Shi. Introduction to New Media, Beijing: China Media University Press, 2009.pp23-35(In Chinese)

[2] L. Peng. Introduction to Network Dissemination, China Rennin University Press, 2010, pp33-37. (In Chinese)

[3] X. Yu. Brand Emotion Communication Strategies of Social Media Context, ACADEMIC JOURNAL, 2012, pp 19-20. (In Chinese)

[4] Y.X. Zhu. Communication and Cultural Studies, Beijing: Xinhua Publishing House, 2011, pp 12-14. (In Chinese)

[5] S.X Liu and G.F. Hu. Network Communication and Cultural, Beijing: China Media University Press, 2012, pp13-17. (In Chinese) 